\title{
Rupture of the trachea and bronchi by closed injury
}

\author{
J. T. CHESTERMAN AND P. N. SATSANGI \\ From the Thoracic Surgical Unit, City General Hospital, Sheffield
}

This paper has three objects: (1) A brief clinical review of the subject; (2) an attempt to assess the functional results of conservative surgery; and (3) a discussion on the mechanism of rupture.

It is based on some 200 cases which have been reported in Western European languages, but so many records are incomplete that precise statistics are difficult to obtain.

\section{BRIEF CLINICAL REVIEW}

Tables I to $\mathbf{V}$ give an overall picture of the present position.

\section{COMMENTS ON TABLE I}

1. There is a preponderance of males under 40 affected.

2. The injury practically always involves diffuse antero-posterior compression of the chest.

3. The overall mortality is given as $30 \%$, more than half of whom die within an hour of injury. Some $10 \%$ of those reaching hospital alive succumb (Burke, 1962).

T A B L E I

GENERAL FEATURES

\begin{tabular}{|c|c|c|}
\hline $\begin{array}{l}\text { Age } \\
\text { Sex }\end{array}$ & $\begin{array}{l}\cdots \\
\cdots\end{array}$ & $\begin{array}{l}1 \text { to } 74 \text { years, usually under } 40 \\
75 \% \text { male } \\
90 \% \text { compression (crushing or deceleration in- } \\
\text { juries) } \\
5 \% \text { c ndoscopic }\end{array}$ \\
\hline Site of injury & . & $\begin{array}{l}80 \% \text { within } 2.5 \mathrm{~cm} \text {. of carina, though all lobar } \\
\text { bronchi have been affected; R. and L. sides } \\
\text { equally affected }\end{array}$ \\
\hline Extent of injury & . & $\begin{array}{l}\text { Trachea-usually linear transverse laceration } \\
\text { Bronchi-usually avulsion } \\
\text { Either may show longitudinal posterior lacera- } \\
\text { tion. } \\
\text { Two lesions may be present } \\
10 \% \text { of those reaching hospital alive }\end{array}$ \\
\hline
\end{tabular}

COMMENTS ON TABLE II

1. There are no associated injuries in $50 \%$ of patients.

2. Fractures of the chest wall are found in only $33 \%$. This is due to the low average age of the
T A B L E I I

ASSOCIATED INJURIES (PATIENTS REACHING HOSPITAL ALIVE)

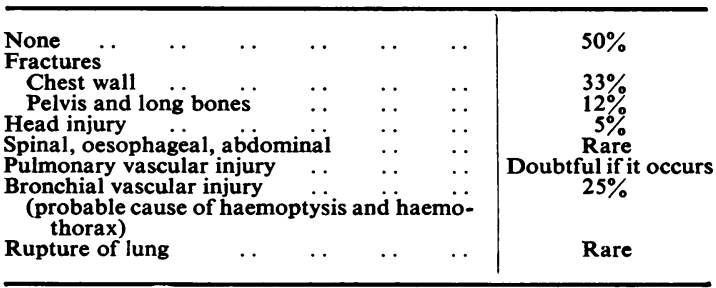

patients and possibly to the poor quality of many radiographs. Fracture of one or more of the first three ribs in a patient over 30 is very suggestive of the possibility of rupture of the air passages, and if rupture is present with fracture of the ribs then one or more of the first five ribs are involved.

3. Rupture of the lung is rare since it is produced by local injury to the chest wall rather than by diffuse compression.

T A B L E I I I

IMMEDIATE CLINICAL FEATURES

\begin{tabular}{|c|c|c|c|c|}
\hline $\begin{array}{l}\text { None .. } \\
\text { Dyspnoea } \\
\text { Pneumothorax } \\
\text { Tension.. } \\
\text { Bilateral } \\
\text { Subcutaneous en } \\
\text { Cyanosis . . } \\
\text { Pain . } \\
\text { Haemoptysis } \\
\text { Shock .. } \\
\text { Cough . . } \\
\text { Haemothorax }\end{array}$ & $\begin{array}{c}\cdots \\
\because \\
\cdots \\
\ddot{\text { nph }} \\
\cdots \\
\cdots \\
\cdots \\
\cdots \\
\cdots\end{array}$ & $\begin{array}{l}\ldots \\
\cdots \\
\cdots \\
\dot{m a} \\
\cdots \\
\cdots \\
\cdots \\
\cdots\end{array}$ & $\begin{array}{l}\ldots \\
\cdots \\
\cdots \\
\cdots \\
\cdots \\
\cdots \\
\cdots \\
\cdots\end{array}$ & $\begin{array}{l}10 \% \\
75 \% \\
66 \% \\
25 \% \\
5 \% \% \\
60 \% \\
30 \% \\
25 \% \\
22 \% \\
15 \% \\
10 \% \\
10 \%\end{array}$ \\
\hline
\end{tabular}

COMMENTS ON TABLE III

1. There is a complete absence of clinical features in $10 \%$ of patients.

2. The dangers of surgical emphysema, giving rise to sudden bilateral pneumothorax, and of bronchial obstruction from haemoptysis do not seem to be sufficiently appreciated and have been the major causes of hospital mortality. 
3. Spasms of coughing with a little bloodstained sputum are suggestive of a partial tracheal rupture.

4. Suggestive radiological findings are $(a)$ an abnormal outline of the air in the trachea and bronchi ; (b) mediastinal emphysema; and (c) fracture of the upper three ribs.

T A B L E I V

TREATMENT-URGENT SURGERY

\begin{tabular}{ll|l}
\hline 1. Tracheostomy & $\ldots$ & $\begin{array}{l}\text { Severe haemoptysis } \\
\text { Pneumothorax, especially tension and } \\
\text { bilateral } \\
\text { Severe surgical emphysema }\end{array}$ \\
3. Thoracotomy & $\ldots$ & $\begin{array}{l}\text { Haemothorax } \\
\text { For haemostasis and prevention of air leak } \\
\text { if the above have not given speedy } \\
\text { control of the situation }\end{array}$ \\
\hline
\end{tabular}

N.B. Bronchoscopy should be done as soon as possible to clear the airway and permit inspection of the injury.

If the rupture is complete, suture immediately.

If the laceration is small and adequately controlled by drainage, watch.

COMMENTS ON TABLE IV

1. If the possibility of rupture exists, bronchoscopy

is urgently required to establish the diagnosis.

2. It is possible to treat small ruptures by drainage only. The author has attempted this once successfully.

3. Rupture may be missed at thoracotomy for haemothorax on account of preoccupation with bleeding (Weisel and Jake, 1953). Careful inspection is necessary after haemostasis has been obtained since clot may occlude the tear (Griffith, 1965). A second rupture may also be present.

T A B LE V

DELAYED COMPLICATIONS OF RUPTURE

\begin{tabular}{ll|l|l}
\hline Partial rupture & $\ldots$ & $\begin{array}{l}\text { May lead to stricture formation, retention of } \\
\text { secretions, sepsis, and bronchiectasis } \\
\text { Leads to complete bronchial obstruction } \\
\text { and collapse distal to it }\end{array}$ \\
\hline Complete rupture &.. & $\begin{array}{l}\text { Treatment } \\
\text { Either resection of stricture and anastomosis } \\
\text { (a graft may be necessary) } \\
\text { Or resection of the diseased lung }\end{array}$ \\
\hline
\end{tabular}

$N . B$. All cases of chest injury must be reviewed for delayed collapse after three months.

COMMENTS ON TABLE $v$ It is important to note that surgical emphysema and pneumothorax may have cleared up and the lung appear to have reexpanded before collapse sets in. This has not been found to occur later than two months after the trauma, so that all cases of compression chest injury should be reviewed for delayed collapse after that period.

\section{FUNCTIONAL RESULTS OF RESTORATION}

We now turn to the functional results of restoration of continuity of the airway. It is pleasing to recollect that it was a member of the Thoracic $\stackrel{\mathbb{}}{\Omega}$ Society, Mr. J. L. Griffith, who first successfully performed a repair of a ruptured bronchus in $\vec{\circ}$ 1948, some eight months after injury, and that this patient had been restored to excellent health when last seen before she emigrated to Australia (Griffith, 1949).

However, restoration of anatomical continuity does not imply recovery of normal function. $\overrightarrow{-}$ Post-operative loss of function may be due to is stricture formation, to the effects of sepsis or $\vec{o}$ oedema of the lung, or to thoracic cage deformity and paralysis. Sepsis is common with stricture though rare with complete obstruction.

Infection or oedema can lead to non-expansion of the lung, to collapse, to increased radio-translucency, or to inadequate function in clinically and radiologically normal lung.

One of Brewer's cases illustrates this last condition. A man aged 24 sustained a crushing injury of the chest. Complete rupture of the right bronchus took place. A repair was done two months later, after which a plain radiograph, bronchogram, and pulmonary angiogram appeared normal, but function tests repeated up to six years later showed that the oxygen uptake of the right lung was only $40 \%$ of the total (Carter, Wareham, and Brewer, 1962 ; case 5).

The pathological process appears to vary and includes destruction, fibrosis, and alteration of the alveolar capillary membrane in part of the lung 0 or in the whole lung. The functional deficiency 3 . may be due either to an arteriovenous shunt or $\delta$ to a subnormal gas exchange in the affected part. The differential diagnosis between the two is 을 made by noting the alteration in oxyhaemoglobin saturation when breathing $100 \%$ oxygen for 10 음 minutes.

It should be pointed out that many of the early $\stackrel{N}{\sigma}$ cases of repair appear to have good functional $N$ results, though very few have had adequate pulmonary function tests performed to prove the 0 status of the affected lung.

Later cases are defined as those operated upon $\frac{\mathscr{C}}{\mathbb{D}}$ for reconstruction of the airway three months or $\stackrel{?}{?}$ more after injury. Only eight such cases have been 0 found in which adequate function tests of each lung separately are available; all these patients $\stackrel{\mathbb{D}}{\circ}$ showed some loss of function of the lung on the $\mathbb{\triangle}$ affected side, though two in later reports were stated to be 'back to normal' but without further 
function tests being mentioned (Razemon and Gernez-Rieux, 1956; Hood and Sloan, 1959).

A typical later case is as follows.

\section{CASE REPORT}

A boy aged 14 fell off a tractor and was run over by its trailer on 1 November 1962. He was taken to hospital and found to have extensive bruising of the anterior chest wall and fractures of both clavicles and the left second to sixth ribs. Radiography in addition showed mediastinal emphysema (Fig. 1). Five months later (26 March 1963) he was sent to me with such severe shortness of breath that he had been unable to attend school for six weeks. Clinically and radiologically he had complete collapse of the left lung (Fig. 2). Bronchoscopy on 28 March showed complete obstruction of the left main bronchus.

On 1 April a left postero-lateral thoracotomy was performed. There were no pleural adhesions and the lung felt normal for a completely collapsed organ. The left pulmonary artery was freed up in case of haemorrhage. The proximal bronchial stump and carina were clearly exposed, after which the distal bronchial stump was dissected out.

The distal stump was opened and much sterile mucus was aspirated, after which a sterile cuffed tube was inserted and both lobes were expanded easily and fully. The proximal stump was then opened and after excision of the damaged area an anastomosis was made with interrupted $\mathrm{O}$ silk sutures. Both lungs were inflated by withdrawal of the right endobronchial tube into the trachea and the wound was closed with intercostal drainage, which was removed after 48 hours.

Convalescence was marred by a staphylococcal infection of the left bronchial tree, necessitating five bronchoscopies and the prolonged use of antibiotics.

A bronchogram on 3 July 1963, three months after operation, was satisfactory (Fig. 3). The patient returned to farm work in October 1963, six months after operation and 11 months after the accident; he is at present at work with no disability (Fig. 4). Eighteen months after operation differential bronchospirometry showed (Table VI) that the average tidal volume, the vital capacity, and the oxygen uptake of

T A B L E V I

BRONCHOSPIROMETRY

\begin{tabular}{|c|c|c|c|c|}
\hline & & & Right Lung & Left Lung \\
\hline 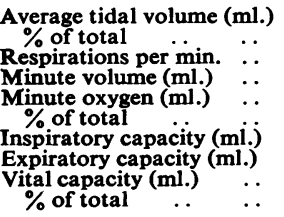 & $\begin{array}{l}\ldots \\
\because \\
\cdots \\
\cdots \\
\cdots \\
\cdots\end{array}$ & $\begin{array}{l}\ldots \\
\because \\
\cdots \\
\because \\
\because \\
\cdots \\
\cdots \\
\cdots\end{array}$ & $\begin{array}{c}300 \\
66 \cdot 6 \\
14 \\
4,200 \\
200 \\
66 \cdot 6 \\
1,300 \\
500 \\
1,800 \\
64 \cdot 3\end{array}$ & $\begin{array}{c}150 \\
33 \cdot 4 \\
14 \\
2,100 \\
100 \\
33 \cdot 4 \\
800 \\
200 \\
1,000 \\
35 \cdot 7\end{array}$ \\
\hline
\end{tabular}

Ear oximetry -rest and exercise-normal oxygen saturations the left lung were only $50 \%$ that of the right lung. A pulmonary angiogram (Fig. 5) shows deficiency of vascularization of part of the left upper lobe which, with subnormal ventilation, accounts for the loss of function. Microscopy of the damaged area showed normal cartilage, muscularis, submucosal, and mucous glands. There was no respiratory mucosa and very little inflammatory reaction, but where present they consist of round-cell foci with fibro-cartilaginous tissue.

Samson's (1956) remarkable case of injury to a child aged 1 year which he repaired after 15 years showed a $20 \%$ oxygen uptake by the right lung three years later, but much of this deficiency may have been due to a chest wall deformity and palsy of the diaphragm on that side.

It may be concluded that restoration of the airway gives better results than resection, but usually some loss of function is detectable by differential pulmonary function tests.

\section{MECHANISM OF RUPTURE}

It has already been stressed that the type of closed injury that produces rupture is one of sudden severe compression of a large area involving the upper anterior chest wall. Experiments on dogs show that the force required to produce rupture by a vertical downward pull was at least $11 \mathrm{~kg}$., whereas a lateral force causing distraction of the carinal region leading to rupture was only $3 \mathrm{~kg}$. (Lloyd, Heydinger, Klassen, and Roettig, 1958).

Clinically, $80 \%$ of closed ruptures take place within $2.5 \mathrm{~cm}$. of the carina, and dog experiments have shown that this is the common type produced by the sudden severe application of pressure over a diffuse area of chest wall either to a supine or to an erect animal whose back is fixed (Table VII).

The mechanism appears to be the sudden compression of the A.P. diameter leading to lateral widening of the chest with distraction of the carinal region. Rupture occurs in a greatly

$$
\text { T A B L E V I I }
$$

MECHANISM OF RUPTURE

\begin{tabular}{l|l|l}
\hline Carinal region $\ldots$ & $\begin{array}{l}\text { Produced by a distracting force greater } \\
\text { than the elasticity of the region. } \\
\text { Crushing injury leading to A.P. com- } \\
\text { pression and lateral widening of } \\
\text { chest. Aided by (1) closed glottis; } \\
\text { (2) inflated lungs; (3) backward dis- } \\
\text { placement of the heart; (4) relative } \\
\text { fixity of carina to pericardium by } \\
\text { broncho-pericardiac membrane and } \\
\text { tracheo-pericardiac ligament } \\
\text { Blow out, tissues everted } \\
\text { Shearing, successive layers being } \\
\text { shifted laterally over each other' } \\
\text { (The Concise Oxford Dictionary) } \\
\text { Distraction or shearing }\end{array}$ \\
Rupture of lobar bronchi. of posterior wall.
\end{tabular}




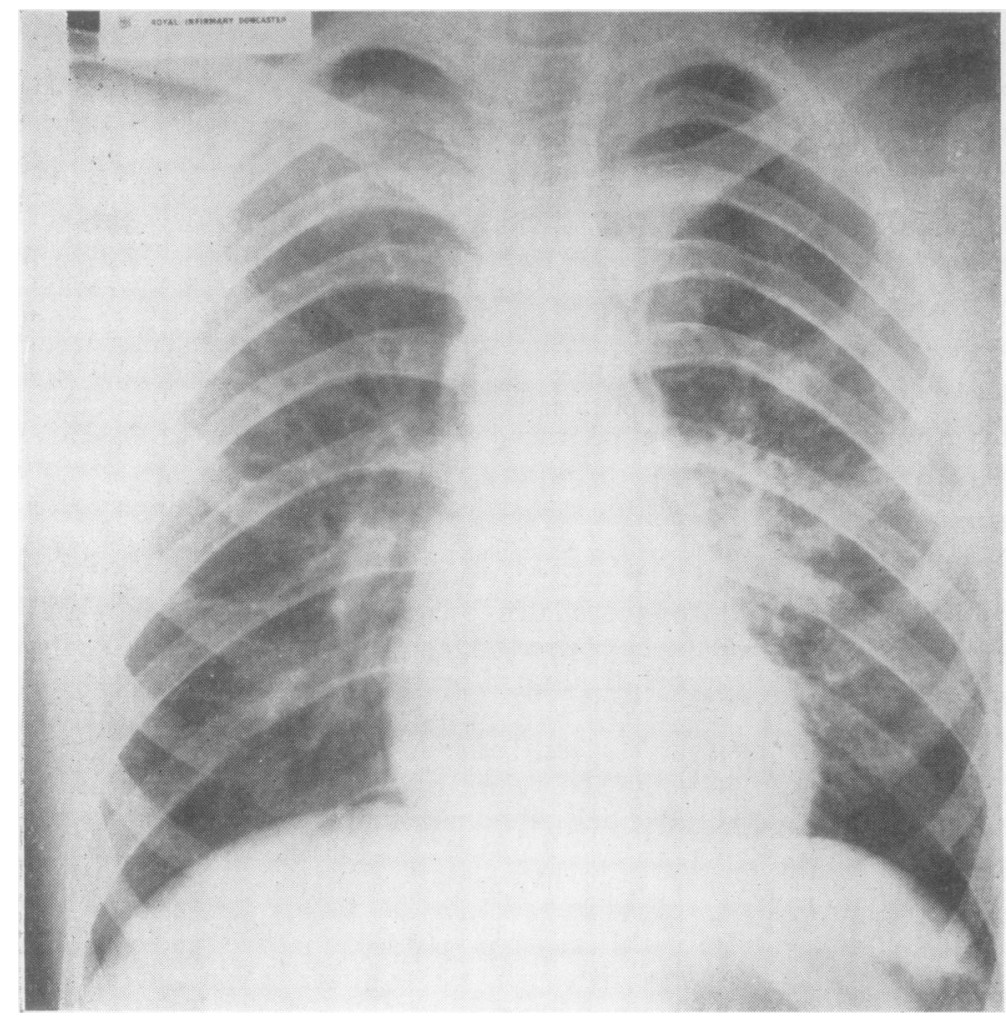

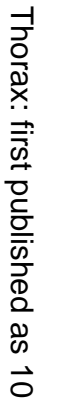

FIG. 1. Mediastinal emphysema, $\overrightarrow{\vec{\nu}}$ fractures of both clavicles, and $\vec{\omega}$ fractures of ribs 2 to 6 on the left side.

FIG. 2. Complete collapse of left lung with gross displacement of the heart to the left.

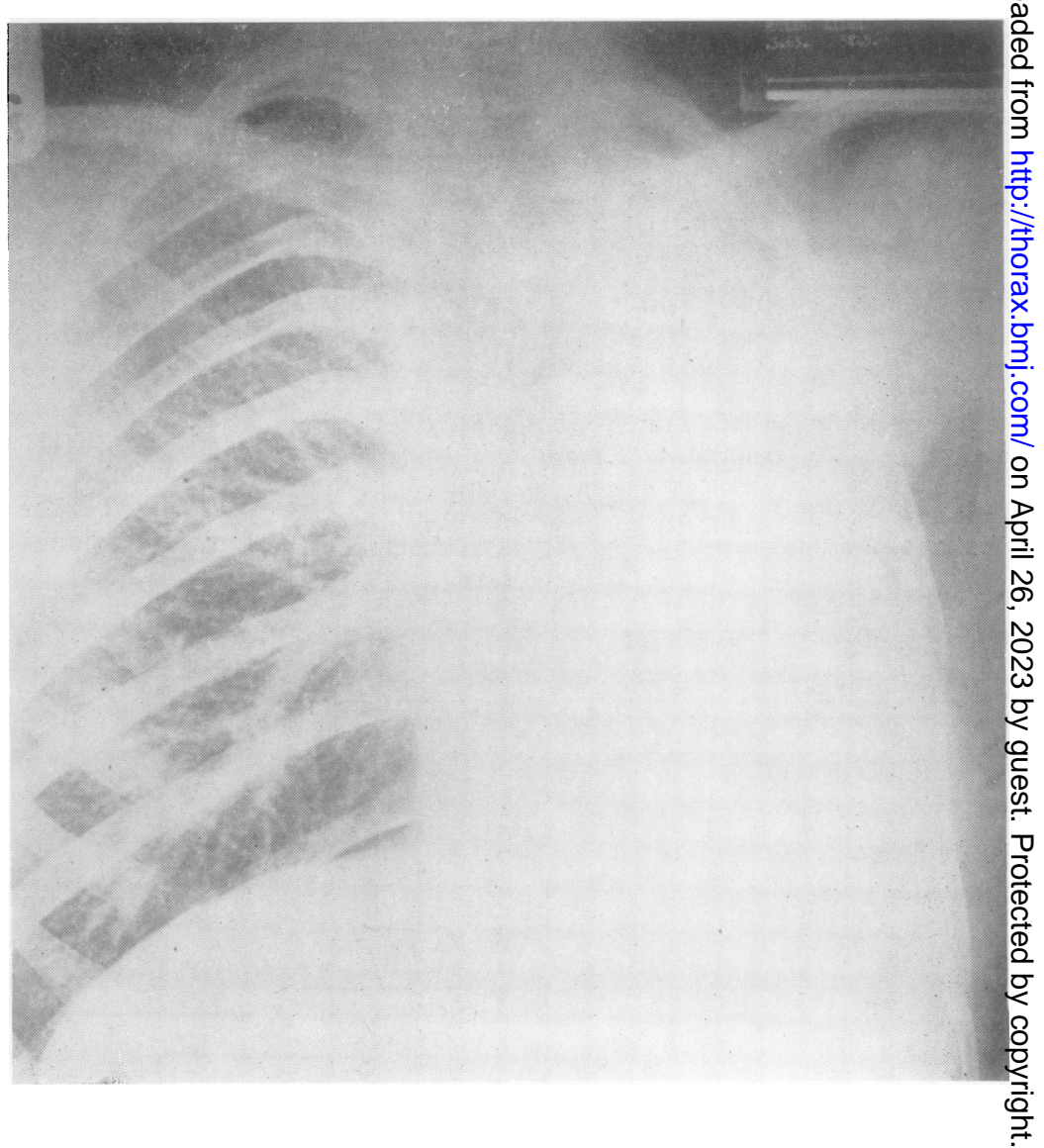




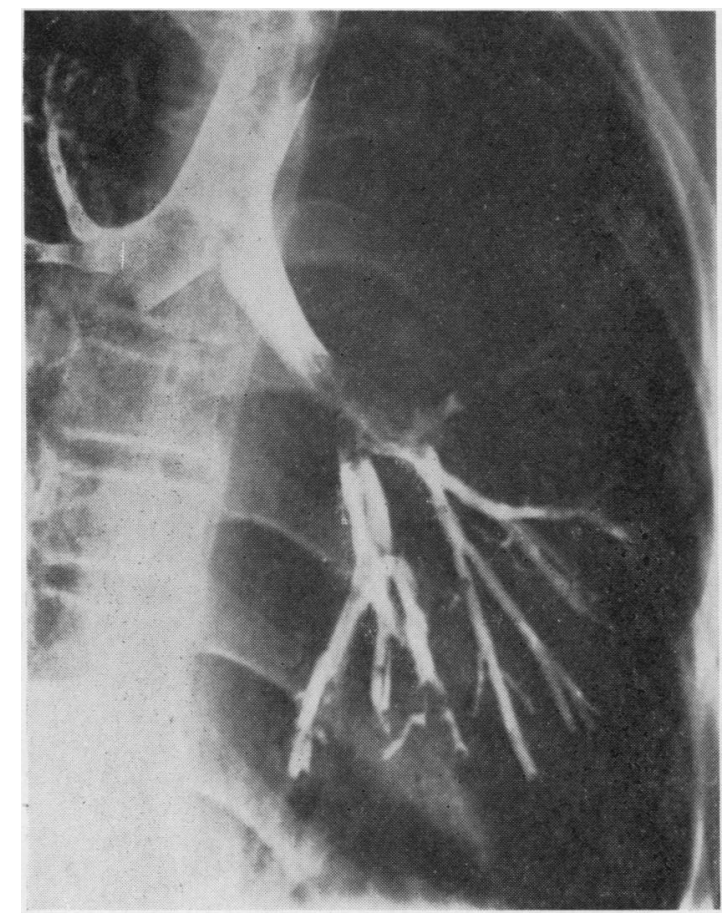

FIG. 3. Bronchogram showing satisfactory repair of the left main bronchus.

FIG. 4. Twenty-six months after conservative surgery.

FIG. 5. Pulmonary angiogram showing deficient vascularization of part of the left upper lobe of the lung. Slightly oblique position.

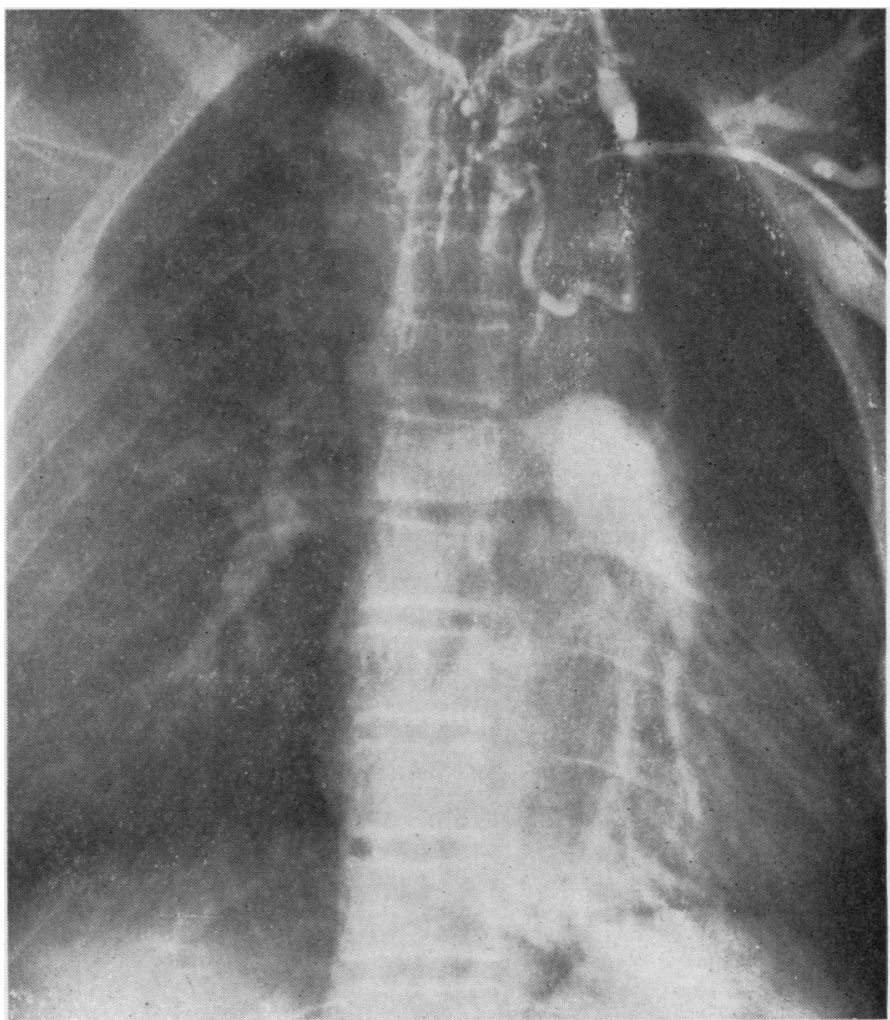

FIG. 5

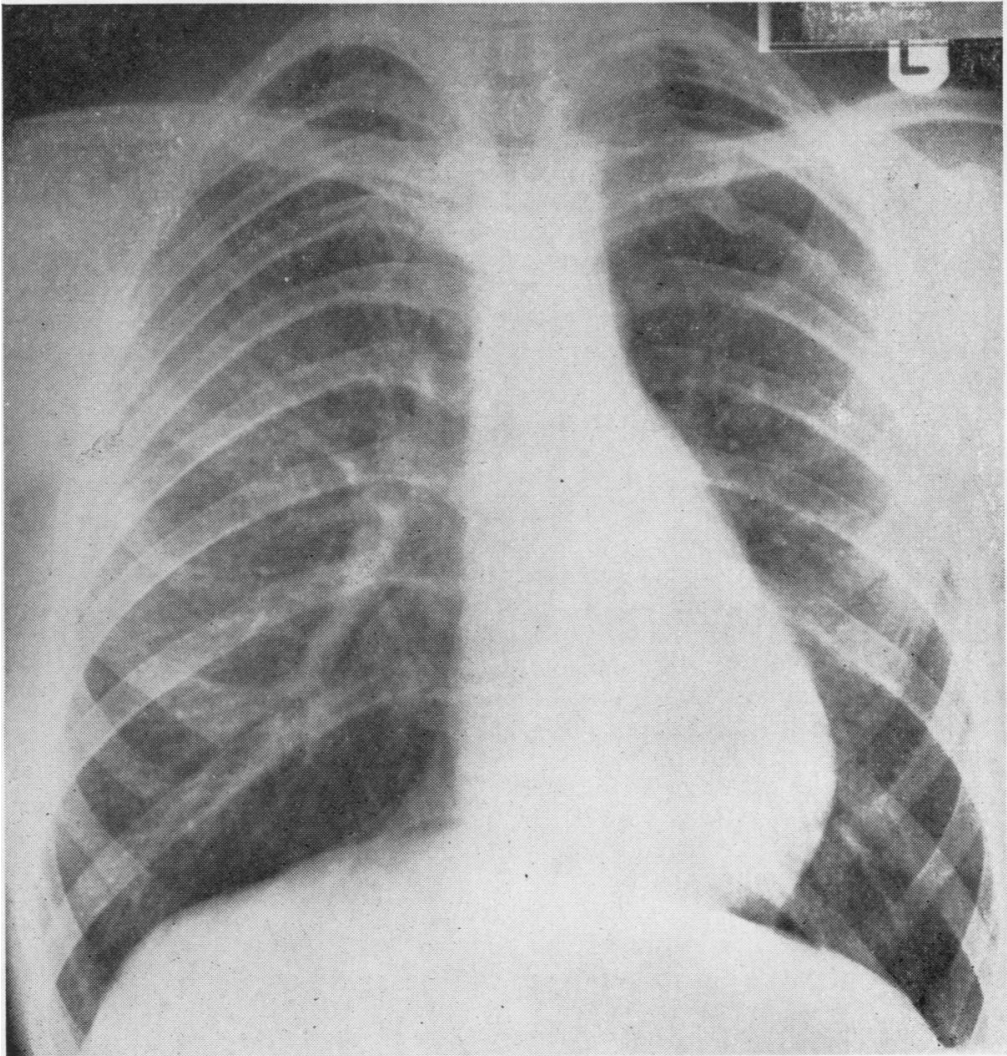

FIG. 4 
increased percentage of dogs when the glottis is closed and the lungs are inflated, since this increases the distraction produced by the injury. The heart at the same time is displaced backwards and to the left, increasing still further the distraction of the bronchi. Finally, the fixity of the carina and the right and left bronchi to the pericardium by the tracheo-pericardiac ligament and the broncho-pericardial membranes increases the forces acting on the region. This gives a satisfactory explanation of the majority of ruptures by closed injury.

Further experimental evidence obtained on dogs shows that sudden inflation of the tracheobronchial tree causes alveolar disruption, never bronchial rupture. There are in human beings occasional cases in which rupture of the posterior wall of the trachea and bronchi is found with typical everted edges, implying an explosive force acting within the air passage (Peters, Loring, and Sprunt, 1958).

This suggests that the compressive force acted while the glottis was closed and the lungs were in an inspiratory phase and so led to tracheobronchial rupture in the larger diameter air passages rather than in the smaller ones in accordance with physical laws.

Rupture of the lobar bronchi is probably due to a combination of distraction and shearing with the possible addition of rotation. Tracheal rupture above the carinal region is probably due to a shearing action - that is, 'successive layers being shifted laterally over each other' (The Concise Oxford Dictionary).

Such a case is well illustrated by a patient of Mr. C. Parish, who gives the following particulars :

'The patient was a 30-year-old ambulance driver, who in his off-duty was driving a taxi through fog in mid-winter when he collided with a lorry and trailer. Some of his passengers were killed and the driver struck the windscreen with his left face and left shoulder, and this shearing force ruptured the trachea between the second and third rings. The skin was not broken. Extensive bruising of the left shoulder and over the whole of the left side of the face confirmed the mechanism of the injury, i.e., the neck was suddenly extended and rotated to the right. A simple skin incision followed by the insertion of a tracheostomy tube was all that was required. The removal of the tube some days later resulted in total healing and he is now back to normal. You will note that there were no bony injuries.' (Fig. 6.)

No evidence of rupture of the trachea has been found in a patient who survived, which could be

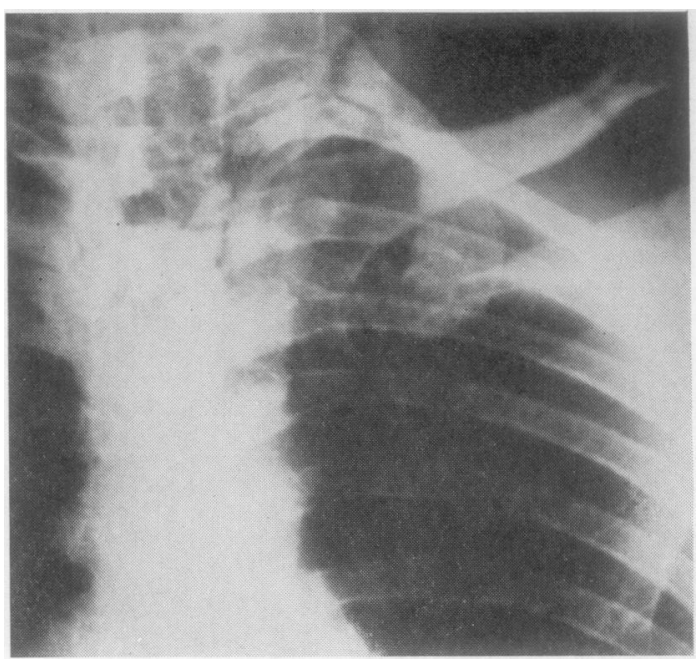

FIG. 6. Surgical emphysema and block in the air outline of the trachea.

attributed to direct compression between the spine and the manubrium sterni.

\section{CONCLUSION}

This condition, if thought of, is readily diagnosed $\overrightarrow{\vec{O}}$ and proved by bronchoscopy.

Conservative surgery gives excellent if not perfect results in suitable cases.

The mechanism of rupture is usually distraction of the carinal region, but in other areas shearing, or laceration from posterior 'blow out', may occur. All types can be produced by a diffuse 3 compressive force applied to the upper anterior chest wall.

Thanks are gratefully recorded to Dr. J. Johnston for his skill in anaesthesia, to Dr. C. S. Darke for N differential pulmonary tests on my patient, and to Mr. J. L. Griffith, of Exeter, and Mr. C. Parish, of $N$ Cambridge, for allowing their cases to be mentioned. N

BIBLIOGRAPHY

Burke, J. F. (1962) Early diagnosis of traumatic rupture of the? bronchus. J. Amer. med. Ass., 181, 682.

Carter, R., Wareham, E. E., and Brewer III, L. A. (1962). Rupture of the bronchus following closed chest trauma. Amer. J. Surg., 104, 177.

Griffith, J. L. (1949). Fracture of the bronchus. Thorax, 4, 105. (1965). Personal communication.

Lloyd, J. R., Heydinger, D. K. Klassen, K. P., and Roettig, L. C. (1958). Rupture of the main bronchi in closed chest surgery Arch. Surg., 77, 597. 
Peters, R. M., Loring, W. E., and Sprunt, W. H. (1958). Traumatic rupture of the bronchus; a clinical and experimental study. Ann. Surg., 148, 871.

Later Conservative Surgery with Adequate Pulmonary Function Tests Campbell, D. C., Swindell, H. V., and Dominy, D. E. (1962). Delayed repair of rupture of the bronchus. J. thorac. Surg., 43, 320.

Hood, R. M., and Sloan, H. E. (1959). Injuries of the trachea and major bronchi. Ibid., 38, 458. (Case 4.)

Mahaffey, D. E., Creech, O., Boren, H. G., and DeBakey, M. E. (1956). Traumatic rupture of the left-main bronchus eleven years after injury. Ibid., 32, 312.
Razemon, P., and Gernez-Rieux, C. (1956). Rupture de la bronche souche gauche datant de quinze mois. Résection-anastomose suivie de récupération fonctionnelle du poumon. Mém. Acad. Suivie de récup
Chir., $82,724$.

Samson, P. C. (1956). Discussion on paper by Mahaffey et al. J. thorac. Surg., 32, 331.

Tyson, M. D., Watson, T. R., and Sibley, J. R. (1958). Traumatic bronchial rupture with plastic repair. New Engl.J. Med., 258, 160.

Weisel, W., and Jake, J. J. (1953). Anastomosis of right bronchus to trachea 46 days following complete bronchial rupture from external injury. Ann. Surg., 137, 220. Quoted by Mahaffey et al., vide supra. J. thorac. Surg., $32,320$. 